\title{
Synovial fibroblast expansion in RA is driven by Notch signalling
}

\begin{tabular}{|c|c|}
\hline $\begin{array}{l}\text { endothelium- } \\
\text { derived Notch } \\
\text { signalling } \\
\text { contributes to } \\
\text { the differentia- } \\
\text { tion and } \\
\text { expansion } \\
\text { of synovial } \\
\text { fibroblasts } \\
\text { in RA }\end{array}$ & $\begin{array}{l}\text { Research now published in Nature } \\
\text { provides new insights into the hetero- } \\
\text { geneity of fibroblasts in the synovium } \\
\text { in rheumatoid arthritis (RA), with } \\
\text { direct relevance to RA pathology } \\
\text { and the therapeutic targeting of } \\
\text { these cells. The findings suggest that } \\
\text { endothelium-derived Notch signal- } \\
\text { ling contributes to the differentiation } \\
\text { and expansion of synovial fibroblasts } \\
\text { in RA, and that modulation of this } \\
\text { signalling pathway could attenuate } \\
\text { inflammation and joint damage. } \\
\text { Previous work by the researchers } \\
\text { had shown that distinct subsets } \\
\text { of fibroblasts in RA correlated } \\
\text { with distinct functions, and that } \\
\text { fibroblasts found in the synovial } \\
\text { lining were predominantly respon- } \\
\text { sible for driving joint injury whereas } \\
\text { fibroblasts in the sublining layer were } \\
\text { responsible for driving inflammation. } \\
\text { Building on these findings, the } \\
\text { new research suggests that lining } \\
\text { and sublining fibroblasts are not } \\
\text { separated into entirely distinct } \\
\text { clusters but exist along a gradient } \\
\text { that corresponds to the anatomical } \\
\text { localization of the fibroblasts in } \\
\text { the synovium, regulated in part by } \\
\text { Notch signalling. }\end{array}$ \\
\hline
\end{tabular}

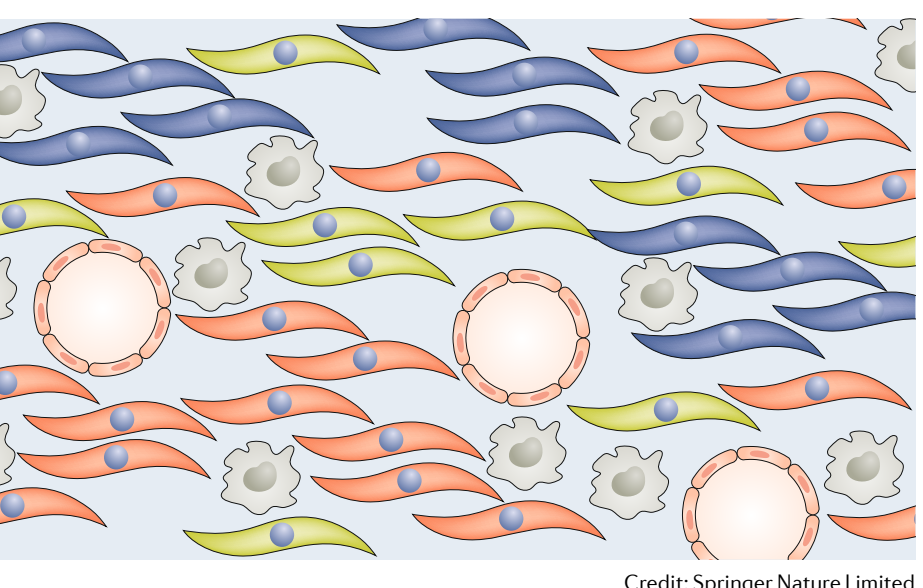

"Here we used single cell RNAseq data to take an unbiased look at fibroblasts and examined their whole transcriptome," explains co-corresponding author Soumya Raychaudhuri. Trajectory transcriptional analyses demonstrated that expression of the synovial lining marker PRG4 (encoding lubricin) and the sublining marker THY1 (encoding CD90) gradually changes along the continuum of synovial fibroblast states.

Anatomically, expression of THY1 was linked with proximity to the endothelium; this positional identity was lost after serial passages ex vivo, suggesting it was determined by the local microenvironment rather than cell-intrinsic factors.

Ligand-receptor analysis of synovial tissue and tissue organoid single-cell RNA-seq datasets suggested endothelium-derived Notch signalling as a potential pathway for driving the differentiation of THY1expressing fibroblasts. In vitro, endothelial cells (which express Notch ligands) induced the expression of NOTCH3 and its ligand Jagged 1 in fibroblasts in a Notch-dependent manner, thereby inducing a fibroblast positional gradient. "Distance from the nearest blood vessel can now be appreciated to be key in understanding fibroblast heterogeneity in the RA synovium, with direct relevance to RA pathology," says co-corresponding author Michael Brenner.

Notably, the researchers found a higher proportion of NOTCH3positive fibroblasts in synovial tissue from patients with RA than in tissue from patients with osteoarthritis, as well as upregulation of Notch target genes in RA synovial tissue.
The researchers then tested whether the genetic deletion of Notch 3 or antibody-mediated blockade of NOTCH3 signalling could attenuate arthritis in mice. "Both approaches abrogated inflammation and joint damage in a mouse model of inflammatory arthritis," recounts Brenner. In the $\mathrm{K} / \mathrm{BxN}$ serum transfer model, arthritis activity and paw swelling was reduced in $\mathrm{Notch}^{-/-}$mice as compared with wild-type mice. Furthermore, twice-weekly administration of an antibody against $\mathrm{NOTCH} 3$ attenuated arthritis severity and joint swelling in wild-type mice, compared with an isotype control antibody.

Raychaudhuri anticipates that researchers will increasingly be examining high-dimensional single-cell data from inflamed tissues, including synovial tissues; such studies could reveal novel therapeutic modalities, particularly in stromal cells, which have been relatively understudied. "In the future it may be possible to apply these same (or similar) technologies to patient samples to prioritize therapies that target specifically the most active or aberrant cell types," says Raychaudhuri.

"Defining fibroblast heterogeneity provides new insight into which cell states and the pathways they express are linked to disease pathology in RA and other diseases," adds Brenner. "This knowledge will better define selective targets for therapeutic intervention against fibroblasts."

Sarah Onuora

ORIGINAL ARTICLE Wei, K. et al. Notch signalling drives synovial fibroblast identity and arthritis pathology. Nature https://doi.org/ 10.1038/s41586-020-2222-z (2020) 